\title{
Divide and conquer: An L-type voltage-gated calcium channel subtype finds a role in conditioned fear
}

\author{
Mark Barad \\ Veterans Health Administration, West Los Angeles, California 90073, USA; Semel Institute of Neuroscience and Human Behavior, \\ University of California, Los Angeles, Los Angeles, California 90095, USA
}

The function of L-type voltage-gated calcium channels (LVGCCs) in learning and memory has been somewhat elusive. For some time we have known that there is progressive decrease in learning and memory with age, and a number of researchers have argued that this is because of a gradual increase in LVGCCs through the life cycle (Barad 2003). Consistent with this observation, LVGCC inhibitors of various types have been observed to improve learning in aged, but not in young animals. Of course, these observations are inconsistent with a role for LVGCCs in promoting learning.

Similarly, the search for an LVGCC-dependent type of longterm potentiation (LTP) has been somewhat frustrating. Since calcium entry into cells is an essential step in many forms of synaptic plasticity including LTP, and since such synaptic plasticity is presumed to be a mechanism underlying learning, it seems reasonable to presume that LVGCCs provide one means of calcium entry contributing to learning. However, a number of labs have found that LVGCC-dependent LTP only occurs in the hippocampus when NMDA receptors are blocked, and when the rate of pathway stimulation is extremely high-at least $200 \mathrm{~Hz}$ (Barad 2003). This is an unlikely scenario in vivo. However, in the amygdala a more physiological pairing of postsynaptic depolarization with presynaptic stimulation of the thalamo-amygdala pathway has been shown to induce an LVGCC-dependent LTP (Weisskopf et al. 1999; Bauer et al. 2002). Other protocols also generate LVGCC-dependent LTP in various amygdala pathways (Lee et al. 2002; Niikura et al. 2004; Fu and Shinnick-Gallagher 2005; Drephal et al. 2006). Thus, the amygdala appears to be a particularly promising location to support for LVGCC-dependent learning.

Regardless of whether physiologically plausible stimulation patterns can generate LVGCC-dependent LTP, the real test of whether these channels play an important role in learning can only come from behavioral tests. In fact, behavioral tests in the past few years have begun to demonstrate a potential role for LVGCCs in several forms of learning, especially using classically conditioned fear, which is well known to depend on the amygdala. Classical, or Pavlovian, conditioned fear of a neutral stimulus, like a tone or the context of conditioning (conditioned stimulus, CS), is created by pairing the CS with an intrinsically aversive unconditioned stimulus (US), typically a footshock. A single pairing of this kind generates robust conditioned fear of the CS that can last a lifetime (Gale et al. 2004). Behavioral scientists measure this fear in increased heart rate, blood pressure, and other physiological changes, as well as in a number of behavioral responses including fear-potentiated startle and freezing, the absence of all movement except breathing - the measure used in the paper from McKinney and Murphy (2006). Conditioned fear can be suppressed or decreased by the repeated presentation of the CS without any US, a process called extinction.

E-mail mbarad@mednet.ucla.edu; fax (310) 206-5855.

Article is online at http://www.learnmem.org/cgi/doi/10.1101//m.402806.
Fear extinction learning shows complete LVGCC dependence, as no extinction occurs when training is performed in the presence of LVGCC inhibitors (Cain et al. 2002; Suzuki et al. 2004). An LVGCC inhibitor infused into the basolateral amygdaloid complex interferes with the consolidation phase of fear conditioning itself (Bauer et al. 2002). That is, freezing to the CS is equal to that of controls immediately after fear conditioning in the presence of LVGCC inhibition, but fear is substantially decreased compared with controls when tested $24 \mathrm{~h}$ later. These distinct roles of LVGCCs in fear conditioning and extinction beg for more thorough dissection, and McKinney and Murphy (2006) provide it.

McKinney and Murphy (2006) provide an elegant example of how genetically modified mice can be used to clarify a confusing field and jump its dissection to a new level of detail. There are two major subtypes of LVGCC in the forebrain, $\mathrm{Ca}_{\mathrm{V}} 1.3$ and $\mathrm{Ca}_{\mathrm{V}}$ 1.2. Since available pharmacological inhibitors do not distinguish between LVGCC subtypes, the dissection of the role of LVGCC subtypes in the brain can only be achieved by genetic means. Such a means recently became available though the generation of mice with genetic inactivation of the pore-forming subunit of one or the other LVGCC subtype, knocking out the function of the channel (Moosmang et al. 2005b). Studies using the $\mathrm{Ca}_{\mathrm{V}} 1.2$ knockout mice demonstrated that this mutation disrupted NMDA-independent late LTP in the mossy fiber-CA1 pathway of the hippocampus (using a 200-Hz tetanus) and disrupted spatial learning (Moosmang et al. 2005a).

McKinney and Murphy (2006) take advantage of the other LVGCC knockout, of $\mathrm{Ca}_{\mathrm{v}} 1.3$, to examine the role of this subtype in fear learning. Although the $\mathrm{Ca}_{\mathrm{V}} 1.3$ knockout mice are deaf, the authors had the luck to find that they are otherwise grossly intact neurologically and behaviorally. Their performance is equivalent to wild-type littermate controls in the rotarod test of vestibular function and reaction speed. It is also equivalent in open-field measures of activity and general anxiety. Thus satisfied with the general neurological and behavioral functioning of the $\mathrm{Ca}_{\mathrm{V}} 1.3$ knockout mice, the authors proceeded to their main interest in the function of LVGCCs in fear learning.

Again, because the $\mathrm{Ca}_{\mathrm{V}} 1.3$ knockout mice are deaf, and because most cue fear conditioning depends on auditory stimuli, the authors elected to focus on contextual rather than cue fear. To generate contextual conditioned fear, the authors placed mice in a novel context for an acclimation period and then administered a single mild footshock. This treatment induces fear of the context measured by freezing when the animals are returned there.

Comparing $\mathrm{Ca}_{\mathrm{V}} 1.3$ knockout mice to wild-type littermates, the authors found that the $\mathrm{Ca}_{\mathrm{V}} 1.3$ LVGCC subtype is crucial for the consolidation, but not the initial formation of conditioned fear of context, as $\mathrm{Ca}_{\mathrm{V}} 1.3$ knockout mice showed fear equal to their littermates at 1 and $6 \mathrm{~h}$ after fear conditioning, but showed significantly less fear than the littermates at $24 \mathrm{~h}$ after conditioning. In a satisfying convergence, the time course McKinney and Murphy (2006) found for the dependence of conditioned fear on 
$\mathrm{Ca}_{\mathrm{V}} 1.3$ parallels the time course found in an experiment testing cue-conditioned fear after infusion of an LVGCC inhibitor into the basolateral amygdala (Bauer et al. 2002). Interestingly, it also parallels the time course of $\mathrm{Ca}_{\mathrm{V}} 1.2$ dependence of long-term spatial memory (Moosmang et al. 2005a).

However, context-conditioned fear depends on both hippocampus and amygdala, while only amygdala appears to be essential for cue-conditioned fear (Phillips and LeDoux 1992). McKinney and Murphy (2006) provide indirect evidence that the defect in the $\mathrm{Ca}_{\mathrm{V}} 1.3$ knockout mice in context-conditioned fear is due to a defect in the amygdala and not in the hippocampus. To do this, they demonstrate that $\mathrm{Ca}_{\mathrm{V}} 1.3$ knockouts are normal in the Morris water maze, a hippocampus-dependent test of spatial learning. While this indirect evidence makes a reasonable case for the involvement of the amygdala, it indicates that choosing context conditioning raised an avoidable problem. Even though the $\mathrm{Ca}_{\mathrm{V}} 1.3$ mice are deaf, they could have been cue conditioned to a visual cue.

In order to compare extinction between animals, it is crucial to start from the same level of fear. However, McKinney and Murphy (2006) found that conditioned fear is significantly reduced in $\mathrm{Ca}_{\mathrm{V}} 1.3$ knockout mice compared with littermate controls $24 \mathrm{~h}$ after a single conditioning shock. In their second bit of luck, the authors found that when they give two training sessions separated by $1 \mathrm{~d}$, conditioned fear of the context is equal for mutants and controls. Thus, the authors could test extinction from an equal starting point in both $\mathrm{Ca}_{\mathrm{V}} 1.3$ knockout mice and in littermate controls. They found no difference between the $\mathrm{Ca}_{\mathrm{V}} 1.3$ knockout mice and their wild-type littermates in extinction either immediately or $24 \mathrm{~h}$ later.

Taken together, these data implicate $\mathrm{Ca}_{\mathrm{V}} 1.3$ in consolidation of conditioned fear, but rule out a role for this subtype in extinction. Again, by exclusion, they likely implicate $\mathrm{Ca}_{\mathrm{V}} 1.2$ in LVGCC-dependent extinction, although other, rarer brain LVGCC subtypes could conceivably be involved. In any case, they demonstrate dissociation at the molecular level between LVGCCs involved in the consolidation of fear conditioning and LVGCCs involved in the extinction of fear.

This molecular dissociation provides a satisfying clarification of the muddy issue of the role of LVGCCs in fear learning. Because the LVGCC subtype involved in fear consolidation is different from that involved in fear extinction, there is no need to reconcile the differences in time course of LVGCC inhibitor effects on conditioning and extinction learning. More importantly, these findings support the idea that fear acquisition and fear extinction involve distinct cellular mechanisms at different synapses, an independence that can explain the return of fear without further training after extensive extinction. This return of fear, with the passage of time, after a stressor or with a change of context, is one of the most striking limitations of extinction learning.

Meanwhile, there is another curiosity about the dependence of the consolidation of fear conditioning on $\mathrm{Ca}_{\mathrm{V}} 1.3$. In order to study extinction, the authors demonstrate convincingly that with more training the $\mathrm{Ca}_{\mathrm{V}} 1.3$ dependence of fear conditioning can be overcome, leaving mutant animals with the same level of fear as their wild-type littermates. McKinney and Murphy (2006) argue that this overtraining effect may explain why they and one other group have shown dependence of fear consolidation on LVGCCs (Bauer et al. 2002), while another group (using five training trials) saw none (Cain et al. 2002). However, there remains the question of why LVGCCs should be necessary only with weak training and only for long-lasting fear memory. One possible explanation follows from the universal dependence of long-term learning on transcription and translation (Pittenger and Kandel 2003). With weak training, calcium entry through the NMDA type of glutamate receptor may be insufficient by itself to signal to the nucleus to initiate long-lasting synaptic strengthening. In that case, L-type channels, activated by the depolarization of the postsynaptic cell, would supplement synaptic calcium to signal the nucleus. However, with strong enough training, NMDA receptors alone might admit enough calcium into the cell to obviate the need for the LVGCCs. This "just so" story is fine, but, of course, it does nothing to explain why extinction, when only CSs are presented, depends completely on LVGCCs. However, since McKinney and Murphy (2006) have shown that $\mathrm{Ca}_{\mathrm{V}} 1.3$ subtype LVGCCs make no important contribution to extinction, we do not need to invoke the same mechanism. We can leave a more detailed discussion of the LVGCC dependence of extinction to a future study.

\section{References}

Barad, M. 2003. Later developments: Molecular keys to age-related memory impairment. Alzheimer Dis. Assoc. Disord. 17: 168-176.

Bauer, E.P., Schafe, G.E., and LeDoux, J.E. 2002. NMDA receptors and L-type voltage-gated calcium channels contribute to long-term potentiation and different components of fear memory formation in the lateral amygdala. J. Neurosci. 22: 5239-5249.

Cain, C.K., Blouin, A.M., and Barad, M. 2002. L-type voltage-gated calcium channels are required for extinction, but not for acquisition or expression, of conditional fear in mice. J. Neurosci. 22: 9113-9121.

Drephal, C., Schubert, M., and Albrecht, D. 2006. Input-specific long-term potentiation in the rat lateral amygdala of horizontal slices. Neurobiol. Learn. Mem. 85: 272-282.

Fu, Y. and Shinnick-Gallagher, P. 2005. Two intra-amygdaloid pathways to the central amygdala exhibit different mechanisms of long-term potentiation. J. Neurophysiol. 93: 3012-3015.

Gale, G., Anagnostaras, S., Godsil, B., Mitchell, S., Nozawa, T., Sage, J., Wiltgen, B., and Fanselow, M. 2004. Role of the basolateral amygdala in the storage of fear memories across the adult lifetime of rats. J. Neurosci. 24: 3810-3815.

Lee, O., Lee, C.J., and Choi, S. 2002. Induction mechanisms for L-LTP at thalamic input synapses to the lateral amygdala: Requirement of mGluR5 activation. Neuroreport 13: 685-691.

McKinney, B.C. and Murphy, G.G. 2006. The L-Type voltage-gated calcium channel Cav1.3 mediates consolidation, but not extinction, of contextually conditioned fear in mice. Learn. Mem. (this issue).

Moosmang, S., Haider, N., Klugbauer, N., Adelsberger, H., Langwieser, N., Muller, J., Stiess, M., Marais, E., Schulla, V., Lacinova, L., et al. 2005a. Role of hippocampal Cav1.2 Ca2+ channels in NMDA receptor-independent synaptic plasticity and spatial memory. $J$. Neurosci. 25: 9883-9892.

Moosmang, S., Lenhardt, P., Haider, N., Hofmann, F., and Wegener, J.W. 2005b. Mouse models to study L-type calcium channel function. Pharmacol. Ther. 106: 347-355.

Niikura, Y., Abe, K., and Misawa, M. 2004. Involvement of L-type Ca2+ channels in the induction of long-term potentiation in the basolateral amygdala-dentate gyrus pathway of anesthetized rats. Brain Res. 1017: 218-221.

Phillips, R.G. and LeDoux, J.E. 1992. Differential contribution of amygdala and hippocampus to cued and contextual fear conditioning. Behav. Neurosci. 106: 274-285.

Pittenger, C. and Kandel, E.R. 2003. In search of general mechanisms for long-lasting plasticity: Aplysia and the hippocampus. Philos. Trans. R. Soc. Lond. B Biol. Sci. 358: 757-763.

Suzuki, A., Josselyn, S.A., Frankland, P.W., Masushige, S., Silva, A.J., and Kida, S. 2004. Memory reconsolidation and extinction have distinct temporal and biochemical signatures. J. Neurosci. 24: 4787-4795.

Weisskopf, M.G., Bauer, E.P., and LeDoux, J.E. 1999. L-type voltage-gated calcium channels mediate NMDA-independent associative long-term potentiation at thalamic input synapses to the amygdala. J. Neurosci. 19: 10512-10519. 


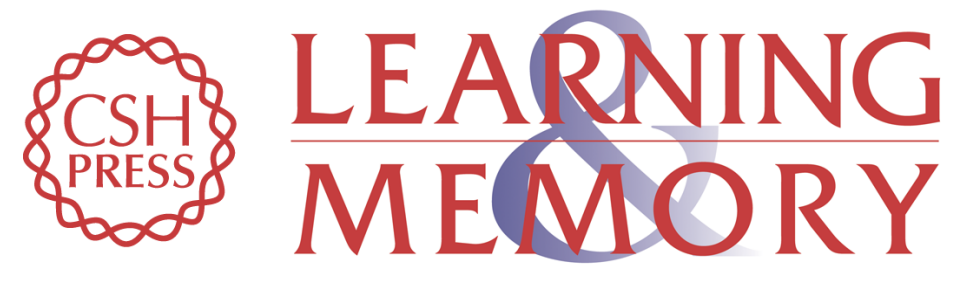

\section{Divide and conquer: An L-type voltage-gated calcium channel subtype finds a role in conditioned fear}

Mark Barad

Learn. Mem. 2006, 13:

Access the most recent version at doi:10.1101//m.402806

References This article cites 14 articles, 6 of which can be accessed free at: http://learnmem.cshlp.org/content/13/5/560.full.html\#ref-list-1

License

Email Alerting Receive free email alerts when new articles cite this article - sign up in the box at the Service top right corner of the article or click here. 